\title{
Electronic gaming as pain distraction
}

\author{
Eleanor Jameson MHSc, Judy Trevena PhD, Nic Swain PhD
}

E Jameson, J Trevena, N Swain. Electronic gaming as pain distraction. Pain Res Manage 2011;16(1):27-32.

The current study investigated whether active distraction reduces participants' experience of pain more than passive distraction during a cold pressor task. In the first experiment, 60 participants were asked to submerge their hand in cold $\left(2^{\circ} \mathrm{C}\right)$ water for as long as they could tolerate. They did this with no distraction, and then with active (electronic gaming system) and passive (television) distraction, in randomly assigned order. Tolerance time, pain intensity ratings and task absorption ratings were measured for each condition. A second experiment attempted to control for participants' expectations about the effects of distraction on pain. Forty participants underwent the same experimental procedure, but were given verbal suggestions about the effects of distraction by the experimenter before each distraction condition. Participants in both experiments had a significantly higher pain tolerance and reported less pain with the active distraction compared with passive or no distraction. Participants reported being more absorbed, and were significantly more willing to do the task again when they had the active distraction compared with both passive distraction and no distraction. They also had more enjoyment, less anxiety and greater reduction in pain with active distraction than with passive distraction. There was no effect of suggestion. These experiments offer further support for the use of electronic games as a method of pain control.

Key Words: Active distraction; Cold pressor; Pain; Pain management

$\mathrm{D}^{\mathrm{c}}$ spite improvements in pain medication, effective pain control continues to be a challenge for many patients and health care professionals. Distraction has emerged as an effective nonpharmaceutical technique for pain control $(1,2)$. Psychological approaches such as distraction may be particularly useful when patients find pharmaceutical treatments inadequate, when medication has negative side effects or as an adjunct therapy. When psychological techniques are effective, pain can be better controlled, dosages of pain medication and related side effects may be reduced, and patient health and well-being increase.

Distraction works through a process of attention. Attentional state is possibly the most commonly studied psychological variable that modifies pain perception (3). The influential gate control and neuromatrix theories of pain both state that attending to pain is one way of increasing the experience of pain $(4,5)$. Further research has shown that people are less likely to notice pain when they are distracted by cognitively demanding tasks (1). In their review, Fernandez and Turk (1) found imagery methods to be the most effective distractions and pain-acknowledging distraction techniques least effective. Using thermal pain, it was found that directing attention toward pain increased the perceived intensity of that pain, while directing attention away from pain decreased intensity and unpleasantness (6). The greater the attentional capacity a distraction demands, the more effective it is at reducing perceived pain, consistent with theories regarding attention as a limited pool of information processing resource (7). In a hospital setting, Levine et al (8) asked patients to rate their postoperative pain more or less often, and found that patients reported more intense pain if they were required to attend to their pain more often.

\section{Les jeux électroniques comme distraction de la douleur}

La présente étude évaluait si une distraction active réduit la douleur que ressentent les participants davantage qu'une distraction passive pendant une épreuve au froid. Pendant la première expérience, 60 participants ont été invités à submerger leur main dans l'eau froide $\left(2^{\circ} \mathrm{C}\right)$ aussi longtemps qu'ils pouvaient le tolérer. Ils l'ont fait sans distraction, avec une distraction active (jeu électronique) et avec une distraction passive (télévision), dans un ordre aléatoire. Les chercheurs ont mesuré la durée de tolérance, le coefficient d'intensité de la douleur et le coefficient d'absorption à la tâche dans chaque situation. Une deuxième expérience visait à contrôler les attentes des participants à l'égard des effets de la distraction sur la douleur. Quarante participants ont subi la même expérience, mais l'expérimentateur leur a donné des suggestions verbales sur les effets de la distraction avant chaque type de distraction. Dans les deux expériences, les participants présentaient une tolérance à la douleur considérablement plus élevée et déclaraient moins de douleur pendant la distraction active que pendant la distraction passive ou s'ils n'avaient pas de distraction. Les participants déclaraient être plus absorbés et étaient beaucoup plus disposés à reprendre la tâche lorsqu'ils étaient exposés à la distraction active plutôt qu'à la distraction passive ou à l'absence de distraction. Ils ressentaient également plus de plaisir, moins d'anxiété et une plus grande réduction de la douleur pendant la distraction active que la distraction passive. La suggestion n'avait aucun effet. Ces expériences étayent davantage l'utilisation des jeux électroniques comme méthode de contrôle de la douleur.

Expectations about pain treatment can also have a significant influence on pain perception. A recent trial by Goossens et al (9) found patients who thought the treatment was highly credible coped with pain better than those who did not, irrespective of treatment condition. Similarly, Staats et al (10) found that participants given verbal positive or negative expectancies of cold pressor pain were significantly different in their tolerance of the pain, with those given beneficial scripts tolerating more pain.

A recent advance in the search for effective distraction has been the use of virtual reality (VR) games, which have been found to be effective in reducing pain (11). Dahlquist et al (11) suggested that interactive distraction is significantly better than passive distraction, although both were effective. Electronic games not only involve visual and auditory sensations, but can also involve tactile and kinesthetic sensations as the game is played, thus increasing attentional demand, consistent with capacity theories of attention. Dahlquist et al (11) used a VR helmet for a distraction procedure, which may also have blocked sensory awareness from surrounding inputs. Additionally, this approach may have had a high level of patient acceptability.

In a recent study of children with cancer, Windich-Biermeier et al (12) found that, given a choice between a range of appealing distracters, two-thirds of children chose a Game Boy (Nintendo Co Ltd, Japan). The current research aims to test the effectiveness of another active distraction technique - the widely available Wii (Nintendo Co Ltd). It can be used by a wide range of people without training and with minimal equipment and cost. We report here on the use of the Wii in a simulated acute pain paradigm to assess its potential utility for adults in a clinical setting. We conducted two experiments, the first to test the Wii as pain distraction. The hypothesis was that the Wii, as a 
form of electronic gaming, would be associated with greater pain distraction than the more passive task of television (TV) watching and would be more distracting than a baseline 'no distraction' condition. Being 'more distracting' would result in a lower rating of pain experience, greater tolerance time, greater task absorption, less pain anxiety, more enjoyment and more willingness to repeat the painful task. Experiment 2 was conducted to see whether any superior effect of gaming could be modified by simple verbal instructions that attempted to manipulate expectations.

\section{METHODS: EXPERIMENT 1}

\section{Participants}

There were 60 participants with ages ranging from 18 to 46 years ( 35 women and 25 men). The mean $( \pm$ SD) age was $24.25 \pm 7.25$ years, with quartiles of 21/22/23 years. The participants were members of the public and students from the University of Otago (New Zealand) who were recruited with posters and through online social networking. The first 40 participants were entered in a draw to win an iPod Shuffle (Apple Inc, USA) for their participation in the $40 \mathrm{~min}$ experimental session, while the final 20 participants received a NZ\$10 gas voucher for their participation. The experimental procedure and participant recruitment was reviewed and approved by the University of Otago Human Ethics Committee (ethical approval reference 07/235). Before beginning the experiment, all participants were given a self-report checklist to indicate whether they had any health problems that might make it dangerous for them to participate (demographic information was also collected). The participant agreement form specifically asked about circulatory problems, skin problems, painful conditions or serious health problems. If participants indicated they had any of these problems, they were not asked to participate in the experiment. Because of the way the experiment was set up (with the cold pressor situated to the left of the participant), only right-handed participants were asked to participate in the experiment.

\section{Procedure}

For the baseline measure of tolerance time, participants were asked to submerge their left hand up to their wrist. The tolerance time was recorded, and the participant rated their pain and absorption. Participants in group 1 were then introduced to the Wii Play 'Bubble' game (Nintendo Co Ltd). Instructions for the game were displayed, and participants practised using the Wii remote. Participants played the game and when they reached level 3, they put their left hand into the water bath, while continuing to play. When participants removed their hand from the water, they also stopped playing the game. Again, tolerance time was recorded by the experimenter, and pain and absorption were noted by the participant. The TV was then turned on, and after 2 min of watching, participants were asked to put their left hand in the water again as before, while continuing to watch the TV. A final rating of time, pain and absorption was followed by the final questionnaire. The procedure was identical for group 2 except participants watched the TV first, and then played the Wii game.

\footnotetext{
Measures

Cold pressor: A Classic Series CAT 350-380 digital culture bath (Contherm Scientific Ltd, New Zealand) (cold pressor) was used to induce pain. The cold pressor chilled a $20 \mathrm{~cm}$ deep water bath to $2 \pm 1^{\circ} \mathrm{C}$. The experimenter used a stopwatch to record how long participants left their hand submerged from entry to withdrawal (tolerance time in seconds). Unknown to the participants, there was an upper time limit of $2 \mathrm{~min}$, after which they were asked to remove their hand from the cold water. A jug of warm water $\left(30 \pm 1^{\circ} \mathrm{C}\right)$ was provided for participants to warm their hand following each exposure to the cold water. A towel was also provided, so that the participant could dry their hands before completing the visual analogue scales (VASs) after each task. The room was kept between $19^{\circ} \mathrm{C}$ and $20^{\circ} \mathrm{C}$.

TV and Wii game: Participants were seated approximately $1 \mathrm{~m}$ away from two identical flatscreen TVs - one displayed the TV show, and
}

the other the Wii game. During the TV (passive) condition, participants watched a 2 min segment of the animated video series Dragonball Z (Super Android 13; FUNimation Productions Ltd, USA; 2003). This cartoon was chosen to be visually similar to the Wii game. It was an animated and action-packed segment. The Wii game used called 'Bubble' - was from Wii Play (2007). Pilot testing indicated that Bubble was suitable for adults as a fun and involving game that could be played with one hand, which was necessary so one hand could be immersed in cold water (ability to work with one hand also has clinical generalizability for intravenous injections, etc). No large body movement was required to succeed in the game. The Bubble game was able to be learned easily in a short (approximately $1 \mathrm{~min}$ ) trial.

VAS: After each task, participants rated their pain levels and how interested they were in the task using VASs. For pain, participants were asked to rate how painful they found the task by marking on a $100 \mathrm{~mm}$ line with 'no pain' at one end $(0 \mathrm{~mm})$ and 'most intense pain imaginable' at the other end $(100 \mathrm{~mm})$. The corresponding scale for absorption was labelled 'extremely boring' at one end and 'completely absorbing' at the other. This was intended to be a measure of how interested the participants were in each condition. Ratings were measured and recorded in millimetres from the $0 \mathrm{~mm}$ end of the scale. The VAS has been demonstrated to be a reliable and consistent measure of clinical and experimental pain sensation (13).

Final questionnaire: At the completion of the experiment, participants were asked to answer 12 questions by circling a number between 1 (not at all/never) and 7 (very much/everyday) on a seven-point Likert scale. The questions covered their task enjoyment, anxiety, pain, how often they played such games/watched TV, and how happy they would be doing the tasks again.

\section{Design and analysis}

The experiment was conducted as a within-subjects design. After reading the information sheet and completing the self-report checklist and consent form, participants took part in an initial baseline exposure with no distraction. Next, all participants experienced both active and passive distraction. The order in which they received the distractions was counterbalanced by randomly assigning participants to either active distraction first (group 1) or passive distraction first (group 2). This was performed by paper selection before the participant entered the room. The measured variables included tolerance time (seconds left in water), perceived pain and absorption (using VAS ratings), task enjoyment, anxiety and happiness to repeat the task (using sevenpoint Likert scales).

These data were then entered into an Excel spreadsheet (Microsoft Corp, USA) before being analyzed using SPSS for Windows, version 16.0 (IBM Corp, USA). The hypothesis that playing active electronic games would reduce participants' experience of pain more than passive distraction or control was examined using ANOVAs. When an ANOVA indicated an effect of condition, pairwise comparisons were used to identify significant differences. All pairwise comparisons used the Bonferroni adjustment. Because the assumption of normality underlying the use of the paired $t$ tests with single-scale Likert ratings is questionable, these analyses were also repeated using the relatedsamples Wilcoxon signed-rank test. The significance of the results was identical to that of the paired $t$ test results, so only the latter results were presented.

\section{METHODS: EXPERIMENT 2}

\section{Participants}

There were 40 participants with ages ranging from 18 to 30 years (17 women and 23 men). Exclusion criteria were the same as in experiment 1 . The mean age was $21.38 \pm 2.92$ years, with quartiles of 20/20/22 years.

\section{Procedure}

The general procedure used in this experiment was the same as in experiment 1 . Participants were randomly assigned to an expectation 
TABLE 1

Mean tolerance times and pain and absorption ratings at baseline and during passive and active distraction for experiment $1(n=60)$

\begin{tabular}{lccc}
\hline & Baseline & $\begin{array}{c}\text { Passive } \\
\text { distraction } \\
\text { (television) }\end{array}$ & $\begin{array}{c}\text { Active } \\
\text { distraction } \\
\text { (Wii*) }\end{array}$ \\
\hline Time, s (maximum $120 \mathrm{~s}$ ) & $56.93 \pm 38.12$ & $60.45 \pm 37.25$ & $76.02 \pm 37.34^{\dagger \ddagger}$ \\
Pain, mm (maximum $100 \mathrm{~mm}$ ) & $63.73 \pm 18.15$ & $66.67 \pm 17.88$ & $49.17 \pm 20.29^{\dagger \ddagger}$ \\
Absorption, mm (maximum & $44.50 \pm 25.27$ & $50.67 \pm 21.39$ & $78.90 \pm 14.66^{\dagger \ddagger}$ \\
$100 \mathrm{~mm}$ ) & & &
\end{tabular}

Data presented as mean \pm SD. *Nintendo Co Ltd, Japan; 'S Significantly different from baseline $(P<0.05)$; ${ }^{\ddagger}$ Significantly different from passive distraction $(P<0.05)$

group (active-positive or active-negative) and task order (active first or active second) before they entered the experiment room. The procedure was the same as in experiment 1 ; however, the experimenter's instructions were different, because an attempt was made to manipulate expectations between participants. One-half of the participants were given verbal suggestions about the Wii's ability to reduce pain and TV's ability to increase pain (active-positive), while the others (activenegative) were told the opposite (that the Wii would increase pain, while the TV would decrease pain). The appropriate suggestions were made before the participants started playing. For example, one group was told before the first task that, "It has been found that a typical man or woman may find they have an increased level of pain tolerance when they play the Wii, so they feel less pain while playing Wii than when watching TV" and then before the second task, "It has been found that a typical man or woman may find they have a decrease in pain tolerance when they watch TV, so they feel more pain when watching TV than playing the Wii". Thus, each participant heard the expectation script twice, once before each type of distraction.

\section{Measures}

Measures were identical to those in experiment 1.

\section{Design and analysis}

This experiment was also conducted with a within-subjects design. The design was the same as in experiment 1 , except that a further condition was added. At the same time as randomly assigning active or passive distraction order, expectations biased toward gaming or TV viewing were also randomly assigned.

The analyses were conducted at the same time and in the same way as experiment 1 (see above).

\section{Experiment 1}

\section{RESULTS}

Tolerance time: Mean tolerance times were longer in the active distraction condition $(76.02 \mathrm{~s})$ than in the passive distraction condition (60.45 s) or at baseline (56.93 s; Table 1). A within-subjects ANOVA of condition with three levels (baseline, Wii and TV) indicated that times differed significantly across conditions $(F[2,118]=23.77$, $\mathrm{P}<0.005)$. Pairwise comparisons revealed that tolerance times during active distraction were significantly longer compared with passive distraction $(\mathrm{P}<0.001)$ and baseline $(\mathrm{P}<0.001)$, and that times during passive distraction were not significantly longer compared with baseline $(\mathrm{P}=0.117)$. For all pairwise comparisons between the three conditions (across both studies), the Bonferroni correction means that $P$ values of less than $0.05 / 3=0.0167$ were considered significant.

Pain: The mean pain score was lower with active distraction $(49.17 \mathrm{~mm})$ compared with passive distraction $(66.67 \mathrm{~mm})$ or baseline (63.73 mm; Table 1). A within-subjects ANOVA showed that pain differed significantly across the three levels of condition $(\mathrm{F}[2,118]=52.50, \mathrm{P}<0.005)$. Pairwise comparisons revealed that perceived pain during the active distraction condition was significantly
TABLE 2

Participants' scores for enjoyment, anxiety, pain reduction and happiness to repeat the task for experiment 1 , as rated on Likert scales $(1=$ not at all, $7=$ very much $)(n=60)$

\begin{tabular}{llc}
\hline & $\begin{array}{c}\text { Active } \\
\text { distraction }\end{array}$ & $\begin{array}{c}\text { Passive } \\
\text { distraction }\end{array}$ \\
\hline How much did you enjoy the task? & $5.65 \pm 0.95^{*}$ & $3.17 \pm 1.46$ \\
How anxious did you feel during the task? & $2.43 \pm 1.17^{\star}$ & $3.25 \pm 1.64$ \\
How much did the task reduce pain? & $5.25 \pm 1.24^{*}$ & $2.72 \pm 1.18$ \\
How happy would you be doing the task again? & $4.48 \pm 1.54^{\star \dagger}$ & $2.70 \pm 1.37^{\dagger}$ \\
\hline
\end{tabular}

Data presented as mean \pm SD. *Active distraction is significantly different from passive $(P<0.05) ;{ }^{\dagger}$ Significantly different from how happy to do task again with no distraction $(2.43 \pm 1.42)$

lower compared with the passive distraction condition $(\mathrm{P}<0.001)$ and baseline $(\mathrm{P}<0.001)$. Passive distraction pain ratings did not differ significantly from baseline $(\mathrm{P}=0.202)$.

Absorption: The mean absorption score was $78.90 \mathrm{~mm}$ with the active distraction and $50.67 \mathrm{~mm}$ with the passive distraction and $44.50 \mathrm{~mm}$ at baseline (Table 1). A within-subjects ANOVA showed that absorption differed significantly across the three levels of condition $(\mathrm{F}[2,118]=63.60, \mathrm{P}<0.005)$. Pairwise comparisons revealed that absorption during the active distraction condition was significantly higher than the passive distraction condition $(\mathrm{P}<0.05)$ and than the baseline $(\mathrm{P}<0.005)$. Absorption during the passive distraction condition did not differ significantly from baseline $(\mathrm{P}=0.175)$.

Enjoyment, anxiety, pain reduction and happiness to repeat the task: Ratings for enjoyment, anxiety and pain were compared across active and passive distraction using paired-samples $t$ tests (Table 2). Mean enjoyment scores were greater with active distraction (5.65) compared with passive distraction $(3.17 ; \mathrm{P}<0.01)$. Mean anxiety scores were lower with active distraction (2.43) compared with passive distraction (3.25; $\mathrm{P}<0.01)$. Mean pain reduction was greater for active distraction (5.25) compared with passive distraction (2.72; $\mathrm{P}<0.001)$. Participants also rated how happy they would be doing the task again with active, passive and no distraction. They would be happier to repeat the task if they were assigned to the active distraction (4.48) compared with passive distraction $(2.70 ; \mathrm{P}<0.01)$. Participants were also significantly happier to repeat the task with either the passive or active distraction compared with no distraction ( $\mathrm{P}<0.05$ for both). For pairwise comparisons in both studies, the Bonferroni correction means that $\mathrm{P}$ values of less than $0.05 / 6=0.0083$ were considered to be significant.

Condition order: To look at the effects of condition order, mixed ANOVAs with the within-subject factor of condition (active and passive distraction) and between-subject factor of condition order (passive first and active first) were performed for time, pain, absorption, enjoyment, anxiety, pain reduction and happiness to do the task again scores. None of the condition order terms or the condition by condition order interaction terms were significant (all $\mathrm{P}>0.05$ ).

\section{Experiment 2}

Expectations: Mixed ANOVAs with the between-subjects factor of suggestion (active-positive versus active-negative) and the withinsubjects factor of condition (baseline, active and passive distraction) were conducted to investigate the effects of suggestion on tolerance time, pain and absorption ratings. The main effects of the condition are described in Table 3. There were no effects of suggestion or condition by suggestion interactions on tolerance time, pain or absorption ratings (all $\mathrm{P}>0.40$ ).

Mixed-design ANOVAs with the within-subjects factor of condition (active and passive distraction) and between-subjects factor of suggestion (active-positive or active-negative) were also performed to analyze the effects of suggestion on enjoyment, anxiety and pain reduction scores, and participants' happiness to repeat the task. Main effects of condition are described in Table 4. There were no main effects of suggestion or condition by suggestion interactions (all $\mathrm{P}>0.30$ ). 
TABLE 3

Tolerance times and pain and absorption ratings at baseline, and during passive and active distraction for experiment $2(n=40)$

\begin{tabular}{lclc}
\hline & Baseline & $\begin{array}{c}\text { Passive } \\
\text { distraction } \\
\text { (television) }\end{array}$ & $\begin{array}{c}\text { Active } \\
\text { distraction } \\
\text { (Wii*) }^{*}\end{array}$ \\
\hline Time, s (maximum 120 s) & $53.58 \pm 37.32$ & $65.38 \pm 39.38^{\dagger}$ & $72.00 \pm 40.27^{\dagger}$ \\
Pain, mm (maximum 100 mm) & $62.65 \pm 16.97$ & $61.20 \pm 24.16$ & $49.49 \pm 23.62^{\dagger \ddagger}$ \\
$\begin{array}{l}\text { Absorption, mm (maximum } \\
100 \mathrm{~mm} \text { ) }\end{array}$ & $43.39 \pm 22.00$ & $57.18 \pm 19.47^{\dagger}$ & $74.57 \pm 19.94^{\dagger \ddagger}$ \\
& & &
\end{tabular}

Data presented as mean $\pm S D$. *Nintendo Co Ltd, Japan; ' Significantly different from baseline; ${ }^{\ddagger}$ Significantly different from passive distraction

Tolerance time: Mean tolerance times in both the active (72.00 s) and passive $(65.38 \mathrm{~s})$ distraction condition were longer compared with baseline (53.58 s; Table 3). A within-subjects ANOVA with three levels of condition (baseline, active and passive) indicated that times differed significantly across conditions $(F[2,78]=15.72, \mathrm{P}<0.001)$. Pairwise comparisons revealed that active distraction tolerance times were significantly longer than at baseline $(\mathrm{P}<0.001)$ but not significantly different from passive distraction $(\mathrm{P}=0.077)$. Passive distraction times were also significantly longer than baseline $(\mathrm{P}=0.001)$. For pairwise comparisons in both studies, the Bonferroni correction means that $P$ values of less than $0.05 / 6=0.0083$ were considered significant.

Pain: Mean pain scores were lower with active distraction $(49.5 \mathrm{~mm})$ compared with passive distraction $(61.20 \mathrm{~mm})$ and baseline $(62.65 \mathrm{~mm}$; Table 3). A within-subjects ANOVA showed that pain differed significantly across the three levels of condition $(\mathrm{F}[2,78]=11.68, \mathrm{P}<0.001)$. Pairwise comparisons revealed that perceived pain during the active distraction condition was significantly lower compared with the passive distraction condition $(\mathrm{P}<0.001)$ and baseline $(\mathrm{P}=0.001)$. Passive distraction pain ratings did not differ significantly from baseline $(\mathrm{P}>0.9)$.

Absorption: Absorption scores were higher with active distraction $(74.58 \mathrm{~mm})$ compared with passive distraction $(57.18 \mathrm{~mm})$ and baseline (43.39 mm; Table 3). A within-subjects ANOVA showed that pain differed significantly across the three levels $(F[2,78]=26.86, \mathrm{P}<0.001)$. Pairwise comparisons revealed that absorption during the active distraction condition was significantly higher compared with the passive distraction condition $(\mathrm{P}<0.001)$ and baseline $(\mathrm{P}<0.001)$. Passive distraction absorption ratings were also significantly higher compared with baseline $(\mathrm{P}<0.05)$.

Enjoyment, anxiety, pain reduction and happiness repeating the task: Ratings of enjoyment, anxiety and pain reduction were compared across active and passive distractions using paired-samples $t$ tests (Table 4). Enjoyment scores were greater with active distraction (5.65) compared with passive distraction $(3.98 ; \mathrm{P}<0.001)$. Anxiety scores did not differ significantly between active distraction (2.90) and passive distraction (2.78; $\mathrm{P}=0.625)$. Pain reduction was greater for active (4.92) than passive $(3.15)$ distraction $(\mathrm{P}<0.001)$. Participants were happier to do the task again with active distraction (4.62) compared with passive distraction $(3.55 ; \mathrm{P}<0.01)$. Participants were also significantly happier to do the task again with active distraction compared with no distraction $(3.25 ; \mathrm{P}<0.001)$, but the difference between happiness to repeat the task with no distraction and with passive distraction was not significant $(\mathrm{P}>0.01)$.

Condition order: To look at the effects of condition order, mixed ANOVAs with the within-subject factor of condition (active and passive distraction), and between-subject factors of condition order (active first and passive first) and expectation (active-positive and passive-positive) were performed for time, pain, absorption, enjoyment, anxiety, pain reduction and happiness to repeat the task scores. For endurance time, there was a significant condition $\times$ condition order effect (such that the degree to which times were longer for the active distracter was greater when the active distracter was the second
TABLE 4

Participants' scores for enjoyment, anxiety, pain reduction and happiness to repeat the task for experiment 2, as rated on Likert scales ( $1=$ not at all, $7=$ very much) $(n=40)$

\begin{tabular}{lcc}
\hline & $\begin{array}{c}\text { Active } \\
\text { distraction }\end{array}$ & $\begin{array}{c}\text { Passive } \\
\text { distraction }\end{array}$ \\
\hline How much did you enjoy the task? & $5.65 \pm 1.19^{*}$ & $3.98 \pm 1.59$ \\
How anxious did you feel during the task? & $2.90 \pm 1.55$ & $2.78 \pm 1.56$ \\
How much did the task reduce pain? & $4.92 \pm 1.67^{\star}$ & $3.15 \pm 1.46$ \\
How happy would you be doing the task again? & $4.62 \pm 1.48^{\star \dagger}$ & $3.55 \pm 1.47$ \\
\hline
\end{tabular}

Data presented as mean $\pm S D$. *Significantly different from passive distraction $(P<0.05) ;{ }^{\dagger}$ Significantly different from how happy to do task again with no distraction (3.25 \pm 1.53$)$

condition; $F[1,36]=5.68, P<0.05)$. There was also a significant suggestion by condition order effect, such that times were longer for whichever task was given first if participants were told that the first condition would increase their endurance time $(\mathrm{F}[1,36]=4.86, \mathrm{P}<0.05)$. For pain ratings, there was a significant condition order main effect and a significant condition order by suggestion effect, such that pain ratings were greater overall when the active distracter was first than when it was second $(\mathrm{F}[1,36]=17.33, \mathrm{P}<0.05)$, especially when the active distracter was described as being unhelpful $(\mathrm{F}[1,36]=9.00, \mathrm{P}<0.05)$. None of the other condition order terms or condition order interaction terms were significant (all $\mathrm{P}>0.05$ ).

Combined analysis: The $t$ tests indicated that there was no significant difference between tolerance times in experiment 1 and experiment 2 at baseline $(\mathrm{P}=0.664)$, and during active distraction $(\mathrm{P}=0.661)$ or passive distraction $(\mathrm{P}=0.527)$. The same was true of pain scores $(\mathrm{P}=0.765$, $\mathrm{P}=0.942$ and $\mathrm{P}=0.197$ for baseline, active distraction and passive distraction, respectively) and absorption ratings $(\mathrm{P}=0.821, \mathrm{P}=0.214$ and $\mathrm{P}=0.126$ for baseline, active distraction and passive distraction, respectively).

Ceiling effect: Participants whose hands were still immersed after 2 min in the cold water were instructed to remove them. In experiments 1 and 2 combined, 18 of 100 participants lasted $120 \mathrm{~s}$ in the water at baseline ('ceiling' group: 13 men and five women). An independent samples $t$ test found that this ceiling group did not differ significantly in pain or absorption ratings from the rest of the participants (all $\mathrm{P}>0.05$ ).

\section{DISCUSSION}

Gaming, using the $\mathrm{W}_{\mathrm{ii}}$, was an effective method of pain control in the present study. Experiment 1 examined the effects of active and passive distraction on participants' experience of pain using a cold pressor task. Participants watched a short animated video (passive distraction) and played a Wii game (active distraction) in a randomly assigned order while immersing one hand in cold water. The time participants could leave their hand immersed (pain tolerance), subjective pain ratings, and pain and absorption ratings were collected and analyzed.

The results support the hypothesis that active distraction would alter pain perception to a greater extent than passive distraction. Participants' tolerance times were longer with active distraction compared with passive distraction and baseline. Participants' pain ratings were also lower with active distraction compared with passive distraction and baseline. Furthermore, participants felt more absorbed in the active distraction condition compared with the passive distraction condition and baseline. Previous research has found that participants do not habituate to cold water, so this does not offer an explanation for increasing tolerance and pain intensity (11).

However, in experiment 1 , passive distraction did not differ significantly from baseline. This may have been caused by the choice of a TV program that did not demand sufficient attention from the viewer. It may also be a result of small numbers of participants in the study because the trend is in the expected direction although it failed to meet statistical significance because of wide SDs. 
The results further support the gate control theory and the neuromatrix theory, which suggest that increased cognitive activity can inhibit the transmission of pain signals to the brain $(4,5)$. They are also consistent with a previous review (3) that provided evidence for an association between attention-demanding distractions and pain reduction. A central feature of pain is that it demands attention. Gaming and $\mathrm{TV}$, in the present experiment, provided top-down attentional selection. When pain is presented (bottom-up selection), it captures attention depending on the attentional load of the top-down selection. This neurocognitive model explains why electronic gaming is a more effective distraction from pain than TV viewing (14). It also suggests that effects of attentional training could have longer-lasting effects on the ability of pain to distract from a chosen behaviour.

Participants enjoyed active distraction more than passive distraction. They also felt less anxious when assigned the active distraction. Furthermore, participants believed that active distraction reduced their pain significantly more than passive distraction.

Participants reported that they would be more willing to repeat the cold pressor task if they were given either type of distraction compared with no distraction. Furthermore, participants were more willing to repeat the task with active distraction compared with passive distraction. The finding that people were more willing to repeat a painful experience while playing electronic games may have clinical importance.

It is possible that participants' tolerance times and pain ratings were influenced by their expectations of which would alter their pain perception more. To look at the effects of expectations and demand characteristics, experiment 2 was conducted, in which participants were given suggestions about the effects and benefits of playing the Wii game and watching TV on pain perception. No effect of expectation was found. Results demonstrating the advantage of active over passive distraction replicated those found in experiment 1 . However, it must be noted that although expectations were intended to be manipulated, no test of the effectiveness of the expectations was conducted.

These results support and extend the previous finding that VR gaming is an effective pain distraction (11). Research on the effects of VR gaming as an active distraction from pain have found that it is a consistently effective distraction technique for children and the present experiment extends this finding to adults. However, the majority of published experiments did not include a passive distraction comparison group. Even though distraction per se is better than no distraction, experiments 1 and 2 offer tentative support for the use of active distraction over passive distraction. Witmer and Singer (15) suggested that VR gaming is more effective than other distractions because it is more immersive and engages several senses simultaneously. The Wii is also highly immersive and engages several senses (visual, auditory, tactile and kinesthetic sensations). Our findings are consistent with those of
Wickens (16), who suggested that electronic games have increased potential for pain distraction because of their active nature.

In both experiments, participants enjoyed the active distraction condition more than the passive distraction condition. It is possible that the effects of the active distraction were increased because of the greater appeal and enjoyment of the task, as well as its attentional load. Windich-Biermeier et al (12) found that two-thirds of a sample of 50 children and adolescents selected a Game Boy when given the choice of books, music, VR glasses or the Game Boy. According to McCaul et al (17), the greater the appeal and enjoyment of a distraction activity, the more effective it is at reducing pain. They proposed that an enjoyable distraction task can make enduring pain more tolerable. It is possible that our choice of passive distraction could have been more enjoyable if self-selected to suit participants. The experiment presented did not seek to conclude that a well-chosen TV segment could not be distracting.

There may be some debate about whether cold pressor pain is similar to acute clinical pain. Cold pressor pain varies from clinical pain on a number of important dimensions. Pain is predictable and escapable in laboratory conditions, perhaps limiting applicability to clinical settings. This can be examined in laboratory conditions by replicating these findings using pressure pain or thermal pain (laser burns).

Another potential limitation of this study is the extent to which the results can be generalized to a clinical setting. There is evidence that total changes in VAS scores need to be between $9 \mathrm{~mm}(18)$ and $13 \mathrm{~mm}$ (19) to be clinically relevant. All changes reported here exceeded those limits, independent of statistical significance testing, so concluding that there would be clinical applicability seems appropriate. However, some evidence suggests that a reduction of $33 \%$ on the VAS is necessary for a patient to have a meaningful pain reduction (20). This minimally clinically significant difference does not seem to vary with severity of pain (21), which supports the extension of these findings to be tested in clinical settings.

Future research could be undertaken to assess whether electronic games have similar effects in a range of clinical settings, and with different age groups and cultural groups. The acceptability of such games to patients in painful situations also needs to be assessed. In conclusion, the present study indicates that active distraction methods such as the Wii may have utility in pain management.

ACKNOWLEDGEMENTS: The authors thank all the participants who provided data. They also thank research students Li Shawn Lim and Joon Chin for helping with data collection during the second experiment, as well as the University of Otago Undergraduate Award program (EJ) and Paul Glue for editorial comments.

\section{REFERENCES}

1. Fernandez E, Turk DC. The utility of cognitive coping strategies for altering pain perception: A meta-analysis. Pain 1989;38:123-35.

2. Johnson MH. How does distraction work in the management of pain? Curr Pain Headache Rep 2005;9:90-5.

3. Villemure C, Bushnell MC. Cognitive modulation of pain: How do attention and emotion influence pain processing? Pain 2002;95:195-9.

4. Melzack R, Wall PD. Pain mechanisms: A new theory. Science 1965;150:971-9.

5. Melzack R. From the gate to the neuromatrix. Pain 1999;(Suppl 6):S121-S126.

6. Miron D, Duncan GH, Bushnell M. Effects of attention on the intensity and unpleasantness of thermal pain. Pain 1989;39:345-52.

7. Kahneman D. Attention and Effort. Englewood Cliffs: Prentice-Hall, 1973.

8. Levine JD, Gordon NC, Smith R, Fields HL. Postoperative pain - effect of extent of injury and attention. Brain Res 1982;234:500-4.

9. Goossens MEJB, Vlaeyen JWS, Hidding A, Kole-Snijders A, Evers SMAA. Treatment expectancy affects the outcome of cognitive-behavioural interventions in chronic pain. Clin J Pain 2005;21:18-26.

10. Staats PS, Staats A, Hekmat H. The additive impact of anxiety and placebo on pain. Pain Med 2001;2:267-79.

11. Dahlquist LM, McKenna KD, Jones KK, et al. Active and passive distraction using a head-mounted display helmet: Effects on cold pressor pain in children. Health Psychol 2007;26:794-801.

12. Windich-Biermeier A, Sjoberg I, Dale JC, Eshelman D, Guzzetta CE. Effects of distraction on pain, fear, and distress during venous port access and venipuncture in children and adolescents with cancer. J Pediatr Oncol Nurs 2007;24:8-19.

13. Price DD, Bush FM, Long S, Harkins SW. A comparison of pain measurement characteristics of mechanical visual analogue and simple numerical rating scales. Pain 1994;56:217-26. 
14. Legrain V, Van Damme S, Eccleston C, Davis KD, Seminowicz DA, Crombez G. A neurocognitive model of attention to pain: Behavioural and neuroimaging evidence. Pain 2009;144:230-2.

15. Witmer BG, Singer MJ. Measuring presence in virtual environments: A presence questionnaire.

Presence: Teleoperators and Virtual Environments 1998;7;225-40.

16. Wickens CD. Multiple resources and performance prediction. Theoretical Issues in Ergonomics Science 2002;3:159-77.

17. McCaul KD, Monson N, Maki RH. Does distraction reduce pain-produced distress among college students? Health Psychol 1992;11:210-7.
18. Kelly A-M. Does the clinically significant difference in visual analog scale of pain scores vary with gender, age, or cause of pain? Acad Emerg Med 1998;5:1086-90.

19. Todd KH. Clinical versus statistical significance in the assessment of pain relief. Ann Emerg Med 1996;27:439-41.

20. Jensen MP, Chen C, Brugger AM. Interpretation of visual analog scale ratings and change scores: A reanalysis of two clinical trials of post-operative pain. J Pain 2003;4:407-14.

21. Kelly A-M. The minimum clinically significant difference in visual analogue scale pain score does not differ with pain severity. Emerg Med 2001;18:205-7. 


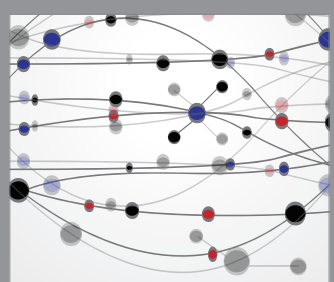

The Scientific World Journal
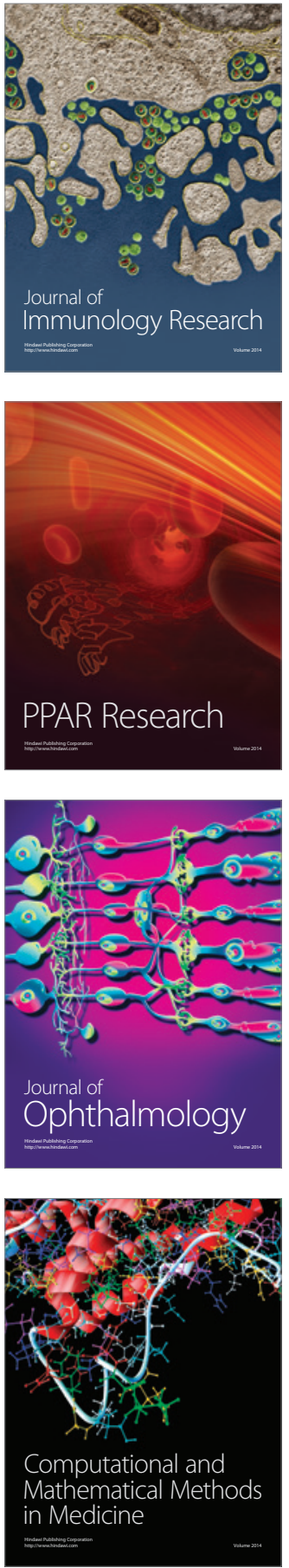

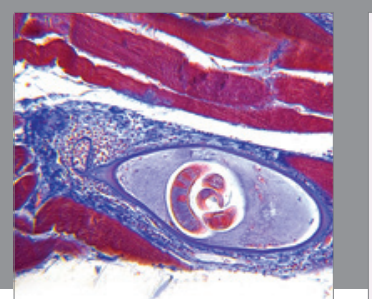

Gastroenterology Research and Practice

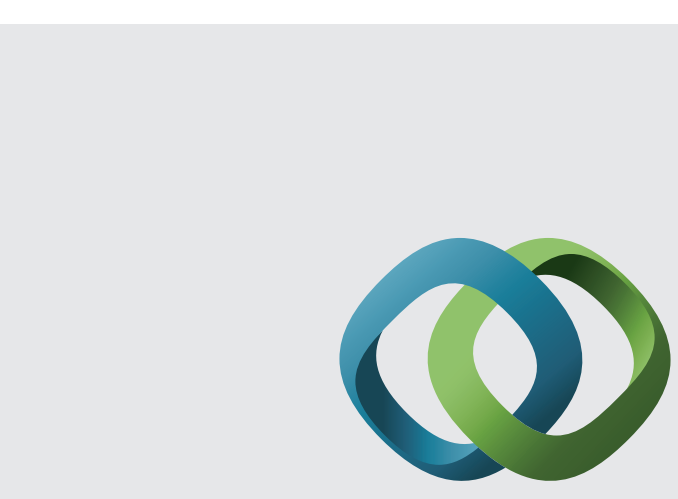

\section{Hindawi}

Submit your manuscripts at

http://www.hindawi.com
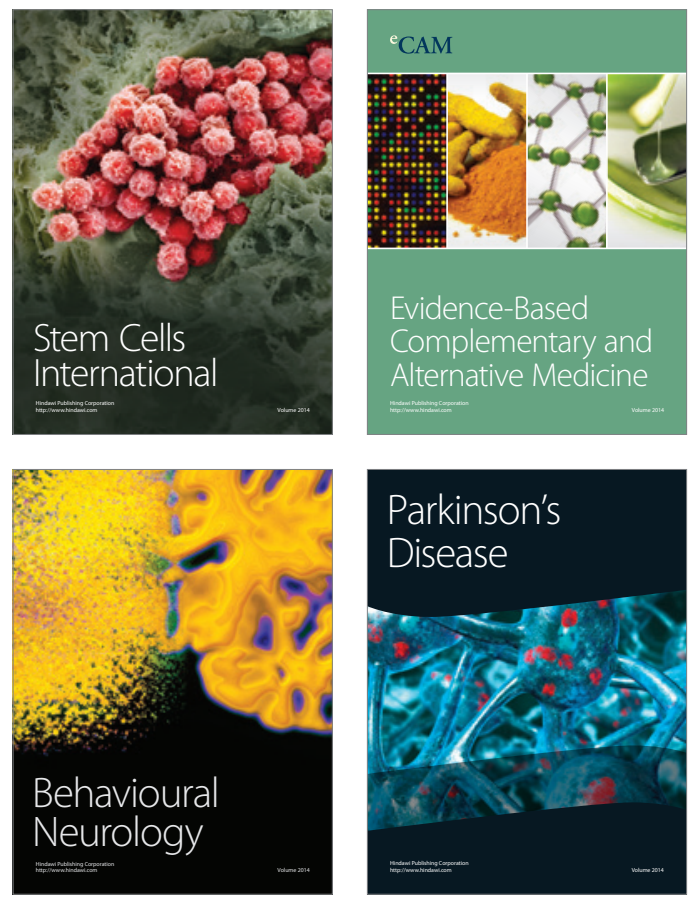
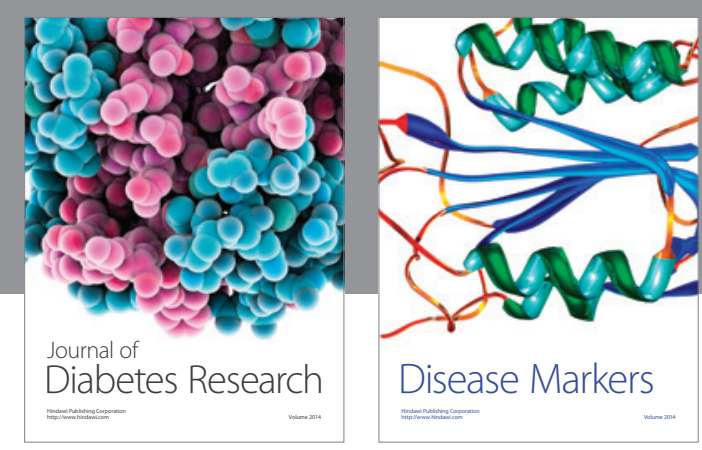

Disease Markers
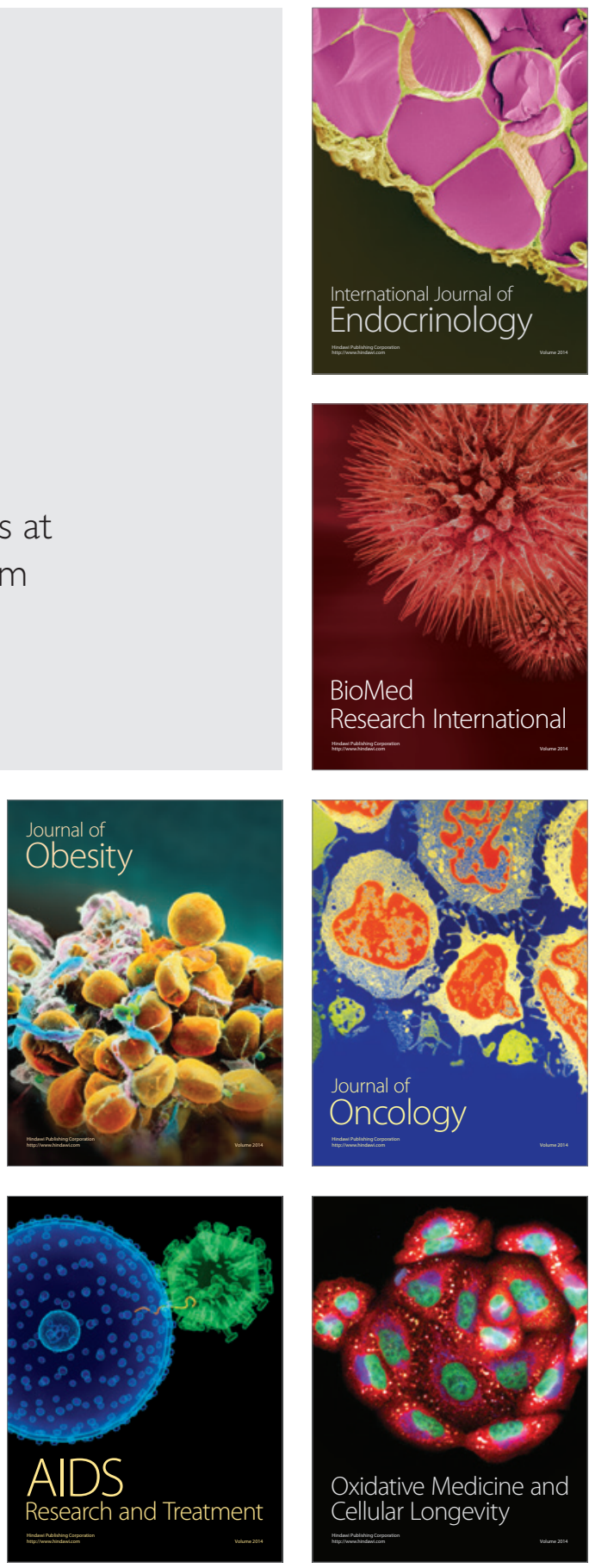